\title{
Gammarus-Microbial Interactions: A Review
}

\author{
Daniel Nelson \\ Aquatic Biology Program, Department of Biological Sciences, The University of Alabama, 1106 Bevill Building, \\ 201 Seventh Avenue, P.O. Box 870206, Tuscaloosa, AL 35487, USA \\ Correspondence should be addressed to Daniel Nelson, dnelson12@crimson.ua.edu
}

Received 14 March 2011; Revised 4 May 2011; Accepted 19 May 2011

Academic Editor: Almut Gerhardt

Copyright (c) 2011 Daniel Nelson. This is an open access article distributed under the Creative Commons Attribution License, which permits unrestricted use, distribution, and reproduction in any medium, provided the original work is properly cited.

Gammarus spp. are typically classified as shredders under the functional feeding group classification. In the wild and in the laboratory, Gammarus spp. will often shred leaves, breaking them down into finer organic matter fractions. However, leaf litter is a poor quality food source (i.e., high $\mathrm{C}: \mathrm{N}$ and $\mathrm{C}: \mathrm{P}$ ratios) and very little leaf material is assimilated by shredders. In freshwater habitats leaf litter is colonized rapidly (within $\sim 1-2$ weeks) by aquatic fungi and bacteria, making the leaves more palatable and nutritious to consumers. Several studies have shown that Gammarus spp. show preference for conditioned leaves over nonconditioned leaves and certain fungal species to others. Furthermore, Gammarus spp. show increased survival and growth rates when fed conditioned leaves compared to non-conditioned leaves. Thus, Gammarus spp. appear to rely on the microbial biofilm associated with leaf detritus as a source of carbon and/or essential nutrients. Also, Gammarus spp. can have both positive and negative effects on the microbial communities on which they fed, making them an important component of the microbial loop in aquatic ecosystems.

\section{Introduction}

The diets of amphipods in the genus Gammarus are variable [1]. For example, Gammarus spp. can serve as detritivores $[2,3]$, herbivores $[4,5]$, predators $[6,7]$, and even cannibals $[2,8,9]$ in aquatic ecosystems. However, under the functional feeding group classification [10-12], Gammarus spp. are typically classified as shredders/facultative shredder collectors [1]. In the wild and in the laboratory, Gammarus spp. often function as shredders consuming leaves and other coarse particulate organic matter (CPOM), breaking it down into smaller fractions or fine particulate organic matter (FPOM). Microbes, such as bacteria and fungi, are often associated with particulate organic matter such as leaves and decaying wood $[13,14]$. Leaf detritus, in particular, is an important carbon source for the microbial loop in aquatic ecosystems [13]. Leaf matter serves as a substrate for bacterial and fungal growth, while at the same time supplying the microbial community with carbon in the form of leached dissolved organic carbon (DOC) [13]. Along with physical abrasion and soluble organic matter leaching, microbial decomposition and invertebrate feeding interact to regulate leaf litter breakdown rate in aquatic ecosystems [15]. Detritus-associated bacteria and fungi are responsible for detrital decomposition and its increase in palatability and nutritional quality to consumers $[11,16,17]$. Invertebrate consumers often rely on the microbial biofilm as a carbon source rather than on the detritus itself $[11,14$, 18]. Cummins [2] refers to CPOM as a "cracker" and its associated microbes as "peanut butter." The CPOM (cracker) acts as a vessel, enabling the consumer to more easily ingest the more nutritious bacteria and fungi (peanut butter).

Over the years, research has shown that Gammarus spp. feed on conditioned or inoculated detritus (i.e., leaves, leaf discs, or sediment) with "suitable" microflora [17, 1922]. In addition, research has shown higher survival and growth rates of Gammarus amphipods in the laboratory when they are fed leaves with fungal growth compared to unconditioned or sterile leaves [20, 23, 24]. Freshly shed and sterile leaves typically have low nutritive value (i.e., high $\mathrm{C}: \mathrm{N}$ and $\mathrm{C}: \mathrm{P}$ ratios) and contain high amounts of lignin and cellulose, which are virtually indigestible to most invertebrates [25]. Therefore, for shredders, the percentage of food ingested and converted into invertebrate biomass is typically very low. As a result, many shredders, including Gammarus amphipods, wait until microbes (which are 
typically highly nutritious) colonize and build up on this poorly nutritious food before feeding.

Gammarus spp. have also been shown to have both negative and positive effects on the microbial communities on which they feed, illustrating the importance of this genus to the microbial loop in lotic and lentic ecosystems. Most research investigating interactions between microbes and invertebrates has been focused on the role of microbes as a potential food source [26]. Although relatively little is known of the feedback effects that grazing invertebrates, such as Gammarus amphipods, can have on their microbial food [26], it has been demonstrated that microbial metabolism, production, and biomass can be influenced by both "bottomup" and "top-down" controls [27-29]. Although invertebrate feeding can decrease microbial biofilm biomass, it has also been shown to stimulate microbial growth and activity [27, 30]. Thus, Gammarus spp. are often involved in a feedback loop with the microbial community on which they feed. In some cases, these feedbacks can be positive [28-30], while in others, they can be negative [29].

The specific objective of this review is to evaluate what is known regarding how microbes influence Gammarus spp. feeding preference, survival, and growth in the laboratory and aquatic habitats. In addition, it will be discussed how Gammarus spp. affect the microbial community on which they feed, either through ingestion or other types of interactions. Finally, the current state of research investigating Gammarus-microbial interactions will be reviewed and possible future research directions will be discussed.

\section{Food Selection, Survival, and Growth}

Quality of detritus is an important factor that determines food selection by shredders. Research has shown that shredders tend to prefer certain leaf species to others [3133] and conditioned leaves over non-conditioned leaves [33-40]. Typically, shredders select food based on several characteristics of leaves, which include toughness, nutrient content, and the degree of conditioning by microbes [40]. Gammarus spp. are no exception [19, 20, 23, 31, 33, 41]. In some of the earliest laboratory experiments investigating food selection by Gammarus spp., Bärlocher and Kendrick [19] investigated food (leaf species) and fungi preference of Gammarus pseudolimnaeus. When very little microflora were present on leaf discs, G. pseudolimnaeus preferred ash to maple and maple to oak leaves. Bärlocher and Kendrick [19] then presented amphipods with pure colonies of ten different hyphomycetes along with maple leaf discs with very little associated microflora. Gammarus pseudolimnaeus always preferred the fungus to the leaf discs and in several cases the amphipods entirely ignored the leaves and consumed only the hyphomycetes.

As Bärlocher and Kendrick [19] demonstrated, G. pseudolimnaeus can exhibit preference for certain conditioned leaf species over others. Other Gammarus spp. have shown similar preferences. In the laboratory, the stygophilic $G$. troglophilus consumed conditioned oak if they were the only leaves presented to it [31]. However, if presented with conditioned oak and elm leaves simultaneously, $G$. troglophilus ingested the elm leaves and ignored the oak. Pöckl [23] simultaneously offered G. fossarum and G. roeseli eight different naturally decaying (i.e., conditioned) leaf species. The most preferred and quickly eaten were leaf discs of lime, ash, and alder. Both species showed little interest in oak leaves, and beech leaf discs were nearly untouched [23]. This behavior most likely resulted from differences in toughness of the leaves, leaf thickness, and chemical constituents (e.g., phenols and tannins) [23].

To determine if G. minus could distinguish different foods and exhibit a preference for the different foods, Kostalos and Seymour [20] performed a series of laboratory and field experiments. They individually compared preference of five different foods against a control, which contained a microflora most similar to fresh stream leaves [20]. The five different foods consisted of elm leaves with no microflora (sterile), bacteria-enriched elm leaves, conditioned elm leaves with a reduced bacterial fauna (still containing fungi), fungus-enriched (Tetrachaetum elegans) elm leaves, and the fungus T. elegans alone. Gammarus minus most strongly preferred the fungus-enriched leaves and conditioned leaves with a reduced bacterial fauna to the control leaves. The sterile elm leaves were least preferred.

In another laboratory study, Friberg and Jacobsen [41] examined the feeding preferences of G. pulex. Overall, G. pulex preferred conditioned alder leaves over five other food items which included conditioned beech leaves, fresh beech leaves, Sitka spruce needles, a fresh macrophyte, and a fresh filamentous green algae. The authors found no linear relationships between food preference and fiber content, toughness, phosphorous content, nitrogen content, and C:N ratio, leading them to believe that bacterial or fungal coating was responsible for the preference patterns. In another study using G. pulex, Graça et al. [42] demonstrated that when offered a choice between unconditioned leaf discs of elm, leaf discs of elm inoculated with the fungus Anguillospora longissima, or A. longissima mycelia, G. pulex was able to discriminate between the different foods and concentrated its feeding on the inoculated leaf discs, and to a lesser extent, on the unconditioned leaf discs. The A. longissima mycelia were ignored by $G$. pulex. Because food preference was not correlated with fungal biomass, leaf disc toughness, leaf decomposition, or nitrogen content, Graça et al. [42] concluded that other unmeasured factors could have affected food preference by G. pulex. These could include the fungal synthesis of micronutrients or the differential ability of fungi to eliminate plant allelochemicals among others [42].

Gammarus spp. have also been shown to prefer particular fungal species to others. When offered leaves colonized separately by one of eight species of aquatic hyphomycetes, Arsuffi and Suberkropp [17] found Gammarus amphipods to be highly selective feeders. Leaves colonized by the fungus Alatospora acuminata were the most preferred, but Gammarus also fed on leaves colonized by Clavariopsis aquatica and Flagellospora curvula. Feeding on other aquatic hyphomycetes was negligible [17]. Aquatic hyphomycetes produce secondary metabolites that function in microbemicrobe interactions and may also defend the fungi from invertebrate feeding. Arsuffi and Suberkropp [17] suggest 
that secondary metabolites from fungi are responsible for the variation observed in feeding preferences, growth rates, and survivorship of shredders consuming leaves colonized by different fungi [17].

The combination of leaf and fungal species has also been shown to influence selection by Gammarus spp. In a laboratory study, individuals of $G$. tigrinus were given a choice between six different leaf/fungus combinations [21]. The leaf discs were conditioned with single species of aquatic hyphomycetes and their concentrations of proteins, lipids, and ergosterol (an indicator of fungal biomass) were measured. Although total consumption was not correlated to the lipid or protein content of the leaves or the fungal biomass, G. tigrinus showed a slight preference for some leaf/fungal combinations over others [21]. The authors then extracted fungal mycelia and applied the extracts to unconditioned leaf discs. Gammarus tigrinus preferred naturally conditioned leaf discs to the extract-coated leaf discs, suggesting that natural colonization over time makes the leaf/fungi combination more attractive compared to a rapid assembly of the parts.

In a more recent study, Assmann and Elert [22] examined the role of fungal attractants and repellents in food preference of the amphipod G. roeseli. Because both attractants and repellents seemed to act on $G$. roeseli feeding preference, the authors suggest that the relative ratios of repellents and attractants might determine consumption of fungi by Gammarus. Furthermore, changes in the environment could lead to changes in the relative ratio of attractants to repellents [22]. Thus, food preference may be governed by environmental conditions rather than being fixed in the consumer.

Amphipods fed conditioned leaves and/or fungi have increased assimilation efficiencies. Low assimilation efficiency results in less matter and energy available for maintenance, growth, and reproduction [43], thus compromising performance. Bärlocher and Kendrick [44] compared the assimilation efficiencies of G. pseudolimnaeus fed elm leaves, maple leaves, or the mycelium of one of ten fungi (5 aquatic hyphomycetes and 5 terrestrial hyphomycetes). Although the amount of food consumed was ten times greater in all of the leaf diets than in the fungi diets, the highest assimilation efficiencies were found for those individuals fed four of the ten fungi. Only $10 \%$ of the dry mass, $14-18 \%$ of the protein, and $17-19 \%$ of the energy of either elm or maple leaves were assimilated by the amphipods. However, G. pseudolimnaeus assimilated approximately $43-76 \%$ of the dry mass, $73-96 \%$ of the protein, and $70-83 \%$ of the energy when fed fungal mycelium commonly found in streams [44].

Research has shown higher survival and growth rates when Gammarus spp. are fed conditioned leaves compared to non-conditioned or sterile leaves. In addition to their experiments on food preference, Kostalos and Seymour [20] experimentally tested the survival of G. minus on ten different diets. These experiments showed significant differences in survivorship over a ten-week period, with the highest survivorship (45-88\%) occurring on fungusenriched leaves [20]. Intermediate survival rates (36-63\%) occurred on leaves with a viable bacterial flora while the lowest survivorship $(\sim 3 \%)$ occurred on leaves that had no or a reduced microflora [20]. Other Gammarus spp. have shown higher growth rates when fed conditioned leaves. Graça et al. [33] found that conditioning had a significant effect on the growth of G. pulex. Similarly, Pöckl [23] found that neonates, juveniles, and early adults of $G$. fossarum and $G$. roeseli fed leached and decaying leaves of lime, elm, and hornbeam with surface growth of aquatic fungi and bacteria had higher growth rates than amphipods fed fresh, growing leaves. These studies suggest that microbes, particularly fungi, confer an advantage to Gammarus spp. by positively influencing survival, growth rates, or both.

In contrast, Graça et al. [24] found no significant increase in the survival of G. pulex on fungally conditioned leaf material when compared to unconditioned food. In general, survival of G. pulex was low on both conditioned and unconditioned leaves [24]. Although growth rates were higher on conditioned leaf material, the difference was not significant [24]. The authors offered an explanation for this lack of significance, using the results of an energy budget study. Individuals of G. pulex feeding on unconditioned leaves had a significantly lower respiration rate than those individuals feeding on conditioned leaves. The authors hypothesized that the lower metabolic demands as a result of a lower respiration rate compensated for the reduced energy intake. Thus, G. pulex is able to maintain a constant growth rate, even when food quality is poor.

\section{Effects of Feeding on the Microbial Community}

The effect Gammarus spp. have on microbial communities is not well known. Obviously, Gammarus amphipods can influence microbial biomass and production through mechanical removal (i.e., direct consumption). Direct consumption of biofilms by invertebrates has been shown to decrease microbial biomass and alter microbial community composition [45-49], however, consumption has also been shown to stimulate microbial growth $[27,30]$. Shredding of leaves by Gammarus spp. may enhance microbial respiration by increasing the surface area of the leaf, which can lead to higher microbial respiration per unit mass of leaves [30]. In addition, increased fragmentation of leaves and excretion by Gammarus amphipods may lead to an increase in the availability of DOC and inorganic nutrients [30]. Thus, if a biofilm is nutrient limited, leaf shredding by Gammarus spp. can possibly relieve nutrient limitation constraints. Direct consumption by Gammarus spp. can not only directly decrease microbial biomass, but it can also change biofilm architecture, thus altering the delivery of inorganic nutrients and energy to the biofilm [29, 49]. Morrison and White [27] showed that microbial biomass was higher on detritus (conditioned oak leaves) that had been grazed by G. mucronatus than on ungrazed detritus. In addition to increasing microbial biomass, grazing by G. mucronatus increased metabolic activity and changed microbial community structure [27]. As amphipods grazed, microbial community structure shifted from one with both prokaryotes (bacteria) and microeukaryotes (fungi) to one dominated by bacteria [27]. Because microbial biofilms are 
important mediators of energy flux and nutrient transformation in aquatic habitats, changes in microbial biomass, community composition, and biofilm architecture may have profound effects on aquatic ecosystem functioning [50, 51].

More recently, Kinsey et al. [30] compared the influence of feeding by cave and surface forms of $G$. minus on microbial biofilms and found that both forms increased the respiration rate of leaf-associated microbes by $32-52 \%$. However, the cave form had a $15 \%$ greater stimulatory effect on microbial respiration. Kinsey et al. [30] concluded that their results may have been due to an attraction of G. minus to leaves with greater microbial growth or due to the amphipods stimulating microbial respiration by (1) increasing the availability of DOM and inorganic nutrients through fragmentation and excretion, (2) increasing water flow over the microbial biofilm, thus reducing boundary layer effects and increasing diffusion rates of nutrients and oxygen into biofilms, or (3) increasing leaf surface area, thereby increasing microbial respiration per unit mass of leaves. Cooney and Simon [29] then used microcosm experiments to examine how bacterial production on rocks and fine sediments from cave streams responded to amendments of dissolved organic matter (DOM) and to the cave form of G. minus. Interestingly, feeding by $G$. minus strongly suppressed bacterial production on rocks but had no effect on bacterial production on fine sediments. In addition, microbial production on rocks was stimulated by DOM amendments but production on sediments was not. Their results indicate that both resources and consumers play important roles in regulating microbial activity, particularly on rocky substrates.

\section{Conclusions}

This paper illustrates the importance of bacteria and fungi in the diet of Gammarus amphipods. It has been shown that Gammarus spp. frequently prefer certain leaf species to others and conditioned leaves to unconditioned leaves. Conditioning of detritus often enhances survival and even growth of Gammarus amphipods. Furthermore, Gammarus can have a significant influence on microbial communities through consumption of microbially enriched detritus, particularly fallen leaves. Although there is a body of literature on the interactions between Gammarus spp. and microbes, the full story is not complete. As important as Gammarus spp. are to detrital processing and nutrient cycling in aquatic ecosystems, there seems to be a decrease in interest in their interactions with microbes. Given the general paucity of recent information on Gammarus performance (e.g., survival, growth, and fecundity) after being fed bacteria and/or fungi, there should be a renewed interest in research on Gammarus-microbial interactions. More specifically, stoichiometric theory and unsaturated fatty acid analysis have been used by researchers to examine energy flow and growth efficiency in a number of aquatic consumers [52-55].

Future research should address stoichiometric relationships between Gammarus spp. and "conditioned" detritus. Colonization by microbes influences $\mathrm{C}: \mathrm{N}$ and $\mathrm{C}: \mathrm{P}$ ratios of leaf litter [56]. Furthermore, consumers often have lower $\mathrm{C}: \mathrm{N}$ and $\mathrm{C}: \mathrm{P}$ ratios than their food, thus elemental imbalances between detritivores (e.g., shredders) and their food can be common [53, 56-58]. An inadequate supply of one or more nutrients can constrain animal growth and alter their life history [57]. One way in which to examine the nutrient deficiency in consumers is the threshold elemental ratio (TER). Threshold elemental ratios are elemental ratios at which growth limitation of a consumer switches from one element to another $[52,57]$. Calculation of TERs (C:N and $\mathrm{C}: \mathrm{P})$ requires estimates of assimilation efficiencies for $\mathrm{C}$, $\mathrm{N}$, and $\mathrm{P}$, ingestion rates, respiration rates, and $\% \mathrm{C}, \% \mathrm{~N}$, and $\% \mathrm{P}$ of consumers. When the TER of the consumer is equal to the C:nutrient ratio of the consumer's food, animal growth is limited by both $\mathrm{C}$ and the nutrient [53]. When the TER of the consumer deviates from the C:nutrient ratio of the food, either $\mathrm{C}$ or the nutrient is limiting [53]. Further elucidation of the importance of highly nutritious microbes in Gammarus diets could be provided by identifying the critical C:N or $\mathrm{C}: \mathrm{P}$ ratios of detritus and microbes and the TERs of Gammarus spp.

Fatty acids (e.g., polyunsaturated fatty acids (PUFAs) and highly unsaturated fatty acids (HUFAs)) are critical biological compounds in aquatic food webs [58, 59]. Some fatty acids are critical for growth and reproduction while others are thought to maintain membrane fluidity at low temperatures [59]. However, little is known about the fatty acid requirements for Gammarus spp. in lakes and streams. Gammarus spp., like other invertebrates, have fatty acid requirements that must be filled through their diet as evidence for synthesis de novo has not been found. Future research should address the trophic transfer of essential fatty acids from microbes to Gammarus amphipods, as this research could make important contributions to Gammarusmicrobe food web ecology and to our understanding of the microbial loop.

\section{Acknowledgments}

The author wishes to thank Frank M. Wilhelm and Chau D. Tran for insightful comments on an earlier version of this paper. In addition, this paper was greatly improved by comments from an anonymous reviewer.

\section{References}

[1] C. Macneil, J. T. A. Dick, and R. W. Elwood, "The trophic ecology of freshwater Gammarus spp. (Crustacea: Amphipoda): problems and perspectives concerning the functional feeding group concept," Biological Reviews of the Cambridge Philosophical Society, vol. 72, no. 3, pp. 349-364, 1997.

[2] G. W. Minshall, "Role of allochthonous detritus in the trophic structure of a wodland springbrook community," Ecology, vol. 48, pp. 139-149, 1967.

[3] D. Nelson, Food web structure of cave streams in southwestern Illinois and the survival and growth of the stygophilic Gammarus troglophilus (Crustacea: Amphipoda) under laboratory conditions, M.S. thesis, University of Idaho, Moscow, Idaho, USA, 2010.

[4] J. W. Moore, "The role of algae in the diet of Asellus aquaticus L. and Gammrus pulex L," Journal of Animal Ecology, vol. 44, pp. 719-730, 1975. 
[5] H. Orav-Kotta, J. Kotta, K. Herkül, I. Kotta, and T. Paalme, "Seasonal variability in the grazing potential of the invasive amphipod Gammarus tigrinus and the native amphipod Gammarus salinus (Amphipoda: Crustacea) in the northern Baltic Sea," Biological Invasions, vol. 11, no. 3, pp. 597-608, 2009.

[6] D. C. Culver and D. W. Fong, "Species interactions in cave stream communities: experimental results and microdistribution effects," American Midland Naturalist, vol. 126, pp. 364379, 1991.

[7] F. M. Wilhelm and D. W. Schindler, "Effects of Gammarus lacustris (Crustacea: Amphipoda) on plankton community structure in an alpine lake," Canadian Journal of Fisheries and Aquatic Sciences, vol. 56, no. 8, pp. 1401-1408, 1999.

[8] J. T. A. Dick, I. Montgomery, and R. W. Elwood, "Replacement of the indigenous amphipod Gammarus duebeni celticus by the introduced G. pulex: differential cannibalism and mutual predation," Journal of Animal Ecology, vol. 62, no. 1, pp. 79-88, 1993.

[9] J. T. Dick, "The cannibalistic behaviour of two Gammarus species (Crustacea: Amphipoda)," Journal of Zoology, vol. 236, no. 4, pp. 697-706, 1995.

[10] K. W. Cummins, "Trophic relations of aquatic insects," Annual Review of Entomology, vol. 18, pp. 183-206, 1973.

[11] K. W. Cummins, "Structure and function of stream ecosystems," Bioscience, vol. 24, pp. 631-641, 1974.

[12] K. W. Cummins and M. J. Klug, "Feeding ecology of stream invertebrates," Annual Review of Ecology and Systematics, vol. 10, pp. 147-172, 1979.

[13] J. L. Meyer, “The microbial loop in flowing waters," Microbial Ecology, vol. 28, no. 2, pp. 195-199, 1994.

[14] R. O. Hall and J. L. Meyer, "The trophic significance of bacteria in a detritus-based stream food web," Ecology, vol. 79, no. 6, pp. 1995-2012, 1998.

[15] K. S. Simon and E. F. Benfield, "Leaf and wood breakdown in cave streams," Journal of the North American Benthological Society, vol. 20, no. 4, pp. 550-563, 2001.

[16] R. H. Boling, E. D. Goodman, J. O. Zimmer et al., "Toward a model of detritus processing in a woodland stream," Ecology, vol. 56, pp. 141-151, 1975.

[17] T. L. Arsuffi and K. Suberkropp, "Selective feeding by shredders on leaf-colonizing stream fungi: comparison of macroinvertebrate taxa," Oecologia, vol. 79, no. 1, pp. 30-37, 1989.

[18] K. S. Simon, E. F. Benfield, and S. A. Macko, "Food web structure and the role of epilithic biofilms in cave streams," Ecology, vol. 84, no. 9, pp. 2395-2406, 2003.

[19] F. Bärlocher and B. Kendrick, "Fungi and food preferences of Gammarus pseudolimnaeus," Archiv für Hydrobiologie, vol. 72, pp. 501-516, 1973.

[20] M. Kostalos and R. L. Seymour, "Role of microbially enriched detritus in the nutrition of Gammarus minus (Amphipoda)," Oikos, vol. 27, pp. 512-516, 1976.

[21] Q. Rong, K. R. Sridhar, and F. Bärlocher, "Food selection in three leaf-shredding stream invertebrates," Hydrobiologia, vol. 316, no. 3, pp. 173-181, 1995.

[22] C. Assmann and E. V. Elert, "The impact of fungal extracts on leaf litter on the food preference of Gammarus roeselii," International Review of Hydrobiology, vol. 94, no. 4, pp. 484496, 2009.

[23] M. Pöckl, "Laboratory studies on growth, feeding, moulting and mortality in the freshwater amphipods Gammarus fossarum and G. roeseli," Archiv für Hydrobiologie, vol. 134, no. 2, pp. 223-253, 1995.
[24] M. A. S. Graça, L. Maltby, and P. Calow, "Importance of fungi in the diet of Gammarus pulex and Asellus aquaticus. II. Effects on growth, reproduction and physiology," Oecologia, vol. 96, no. 3, pp. 304-309, 1993.

[25] F. Bärlocher, "On trophic interactions between microorganisms and animals," The American Naturalist, vol. 114, pp. 147148, 1979.

[26] P. Kemp, "Potential impact on bacteria of grazing by a macrofaunal deposit-feeder, and the fate of bacterial production," Marine Ecology Progress Series, vol. 36, pp. 151-161, 1987.

[27] S. J. Morrison and D. C. White, "Effects of grazing by estuarine gammaridean amphipods on the microbiota of allochthonous detritus," Applied and Environmental Microbiology, vol. 40, pp. 659-671, 1980.

[28] M. L. Pace and J. J. Cole, "Regulation of bacteria by resources and predation tested in whole-lake experiments," Limnology and Oceanography, vol. 41, no. 7, pp. 1448-1460, 1996.

[29] T. J. Cooney and K. S. Simon, "Influence of dissolved organic matter and invertebrates on the function of microbial films in groundwater," Microbiology of Aquatic Systems, vol. 58, pp. 599-610, 2009.

[30] J. Kinsey, T. J. Cooney, and K. S. Simon, "A comparison of the leaf shredding ability and influence on microbial films of surface and cave forms of Gammarus minus Say," Hydrobiologia, vol. 589, no. 1, pp. 199-205, 2007.

[31] F. Jenio, "The life cycle and ecology of Gammarus troglophilus Hubricht and Mackin,” Crustaceana Supplement, vol. 6, pp. 204-215, 1980.

[32] T. M. Iversen, "Ingestion and growth in Sericostoma personatum (Trichoptera) in relation to the nitrogen content of ingested leaves," Oikos, vol. 25, no. 3, pp. 278-282, 1974.

[33] M. A. S. Graça, C. Cressa, M. O. Gessner, M. J. Feio, K. A. Callies, and C. Barrios, "Food quality, feeding preferences, survival and growth of shredders from temperate and tropical streams," Freshwater Biology, vol. 46, no. 7, pp. 947-957, 2001.

[34] F. J. Triska, Seasonal distribution of aquatic hyphomycetes in relation to the disappearance of leaf litter from a woodland stream, Ph.D. dissertation, University of Pittsburgh, Pittsburgh, Pa, USA, 1970.

[35] N. K. Kaushik and H. B. N. Hynes, "The fate of the dead leaves that fall into streams," Archiv für Hydrobiologie, vol. 68, pp. 465-515, 1971.

[36] J. S. Rounick and M. J. Winterbourn, "Leaf processing in two contrasting beech forest streams: effects of physical and biotic factors on litter breakdown," Archiv für Hydrobiologie, vol. 96, pp. 448-474, 1983.

[37] F. Bärlocher, "The role of fungi in the nutrition of stream invertebrates," Botanical Journal of the Linnean Society, vol. 91, pp. 83-94, 1985.

[38] K. Suberkropp, "Interactions with invertebrates," in The Ecology of Aquatic Hyphomycetes, F. Bärlocher, Ed., pp. 118134, Springer, New York, NY, USA, 1992.

[39] M. A. S. Graça, "Patterns and processes in detritus-based stream systems," Limnologica, vol. 23, pp. 107-114, 1993.

[40] M. A. S. Graça, "The role of invertebrates on leaf litter decomposition in streams-a review," International Review of Hydrobiology, vol. 86, no. 4-5, pp. 383-393, 2001.

[41] N. Friberg and D. Jacobsen, "Feeding plasticity of two detritivore-shredders," Freshwater Biology, vol. 32, no. 1, pp. 133-142, 1994.

[42] M. A. S. Graça, L. Maltby, and P. Calow, "Importance of fungi in the diet of Gammarus pulex and Asellus aquaticus I: feeding strategies," Oecologia, vol. 93, no. 1, pp. 139-144, 1993. 
[43] W. H. Karasov and C. Martinez del Rio, Physiological Ecology, Princeton University Press, Princeton, NJ, USA, 2007.

[44] F. Bärlocher and B. Kendrick, "Assimilation efficiency of Gammarus pseudolimnaeus (Amphipoda) feeding on fungal mycelium or autumn-shed leaves," Oikos, vol. 26, pp. 55-59, 1975.

[45] R. J. Barsdate, R. T. Prentki, and T. Fenchel, "Phosphorus cycle of model ecosystems: significance for decomposer food chains and effect of bacterial grazers," Oikos, vol. 25, no. 3, pp. 239251, 1974.

[46] L. E. Barnese, R. L. Lowe, and R. D. Hunter, "Comparative grazing efficiencies of pulmonate and prosobranch snails," Journal of the North American Benthological Society, vol. 9, pp. 35-44, 1990.

[47] G. J. C. Underwood and J. D. Thomas, "Grazing interactions between pulmonate snails and epiphytic algae and bacteria," Freshwater Biology, vol. 23, no. 3, pp. 505-522, 1990.

[48] N. V. C. Polunin, "The decomposition of emergent macrophytes in fresh water," in Advances in Ecological Research, Volume 14, A. Macfadyen and E. D. Ford, Eds., pp. 115-166, Academic Press, New York, NY, USA, 1984.

[49] J. R. Lawrence, B. Scharf, G. Packroff, and T. R. Neu, "Microscale evaluation of the effects of grazing by invertebrates with contrasting feeding modes on river biofilm architecture and composition," Microbial Ecology, vol. 44, no. 3, pp. 199-207, 2002.

[50] P. J. Mulholland, A. D. Steinman, E. R. Marzolf, D. R. Hart, and D. L. DeAngelis, "Effect of periphyton biomass on hydraulic characteristics and nutrient cycling in streams," Oecologia, vol. 98, no. 1, pp. 40-47, 1994.

[51] T. J. Battin, L. A. Kaplan, J. D. Newbold, and C. M. E. Hansen, "Contributions of microbial biofilms to ecosystem processes in stream mesocosms," Nature, vol. 426, no. 6965, pp. 439442, 2003.

[52] R. W. Sterner, "Modelling interactions of food quality and quantity in homeostatic consumers," Freshwater Biology, vol. 38, no. 3, pp. 473-481, 1997.

[53] R. W. Sterner and J. J. Elser, Ecological Stoichiometery: The Biology of Elements from Molecules to the Biosphere, Princeton University Press, Princeton, NJ, USA, 2002.

[54] M. T. Brett and D. C. Müller-Navarra, "The role of highly unsaturated fatty acids in aquatic foodweb processes," Freshwater Biology, vol. 38, no. 3, pp. 483-499, 1997.

[55] M. Torres-Ruiz, J. D. Wehr, and A. A. Perrone, "Trophic relations in a stream food web: importance of fatty acids for macroinvertebrate consumers," Journal of the North American Benthological Society, vol. 26, no. 3, pp. 509-522, 2007.

[56] W. F. Cross, J. P. Benstead, P. C. Frost, and S. A. Thomas, "Ecological stoichiometry in freshwater benthic systems: recent progress and perspectives," Freshwater Biology, vol. 50, no. 11, pp. 1895-1912, 2005.

[57] P. C. Frost, J. P. Benstead, W. F. Cross et al., "Threshold elemental ratios of carbon and phosphorus in aquatic consumers," Ecology Letters, vol. 9, no. 7, pp. 774-779, 2006.

[58] A. Liess and H. Hillebrand, "Stoichiometric variation in C:N, $\mathrm{C}: \mathrm{P}$, and N:P ratios of littoral benthic invertebrates," Journal of the North American Benthological Society, vol. 24, no. 2, pp. 256-269, 2005.

[59] M. Torres-Ruiz, J. D. Wehr, and A. A. Perrone, "Are netspinning caddisflies what they eat? An investigation using controlled diets and fatty acids," Journal of the North American Benthological Society, vol. 29, no. 3, pp. 803-813, 2010. 

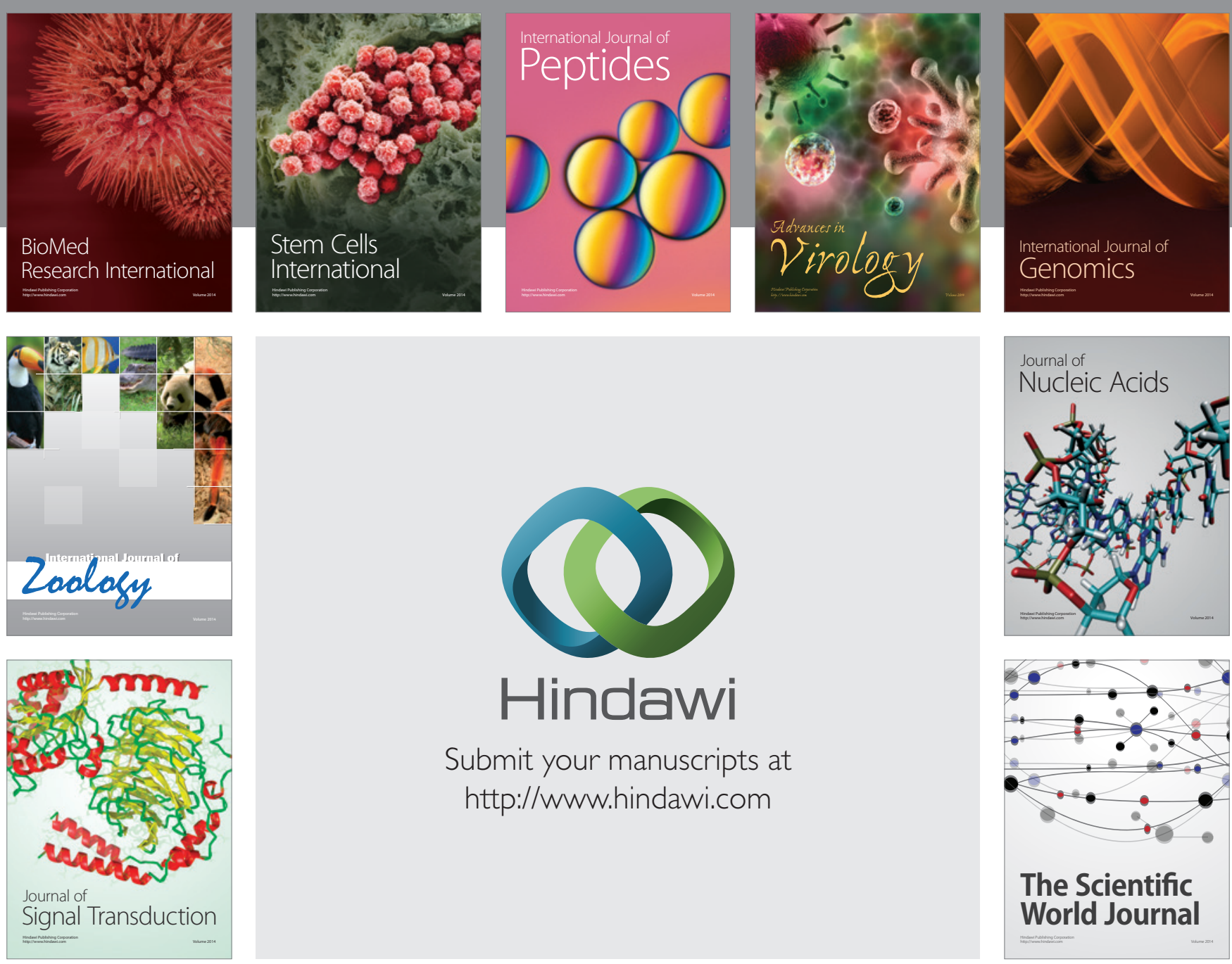

Submit your manuscripts at

http://www.hindawi.com
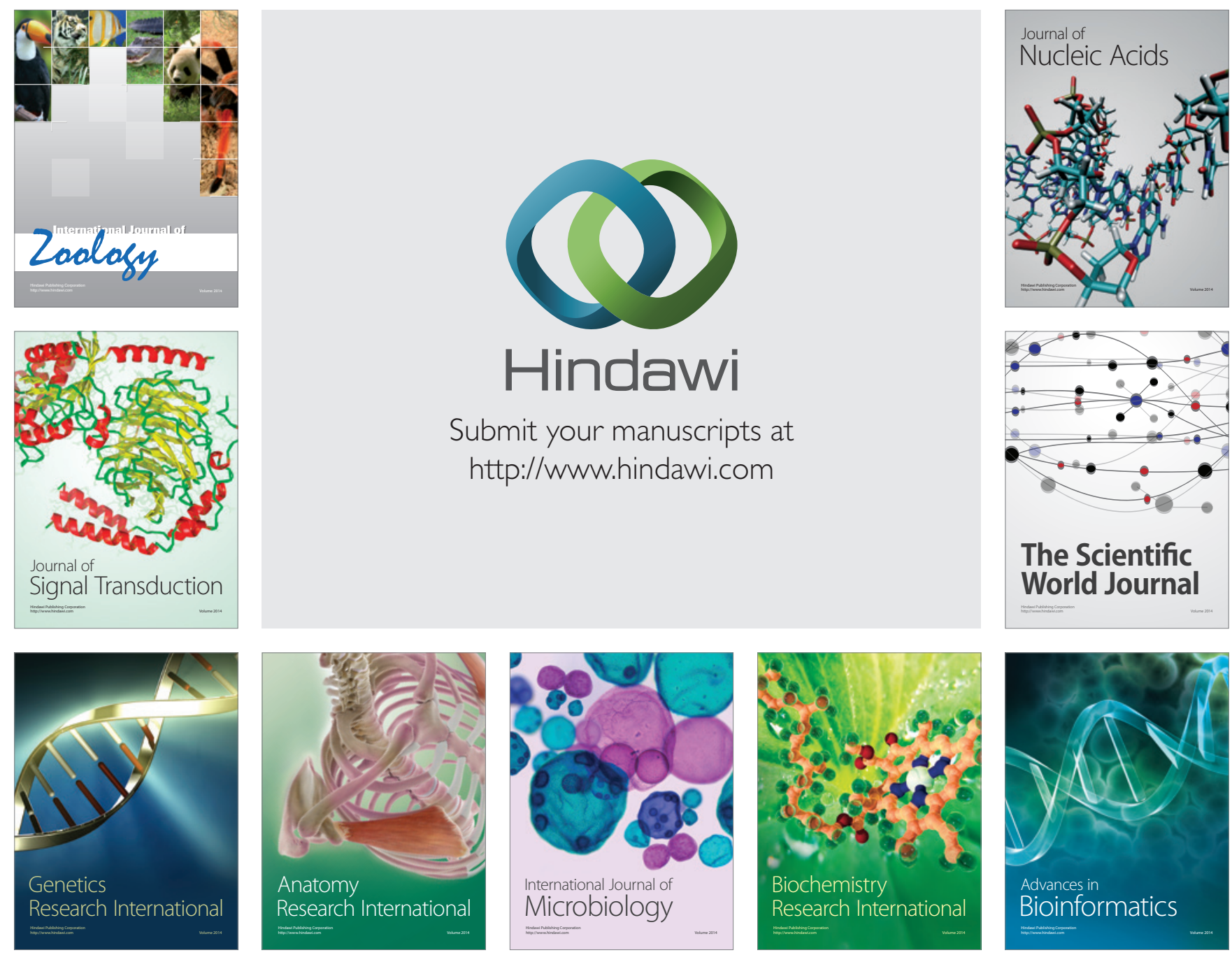

The Scientific World Journal
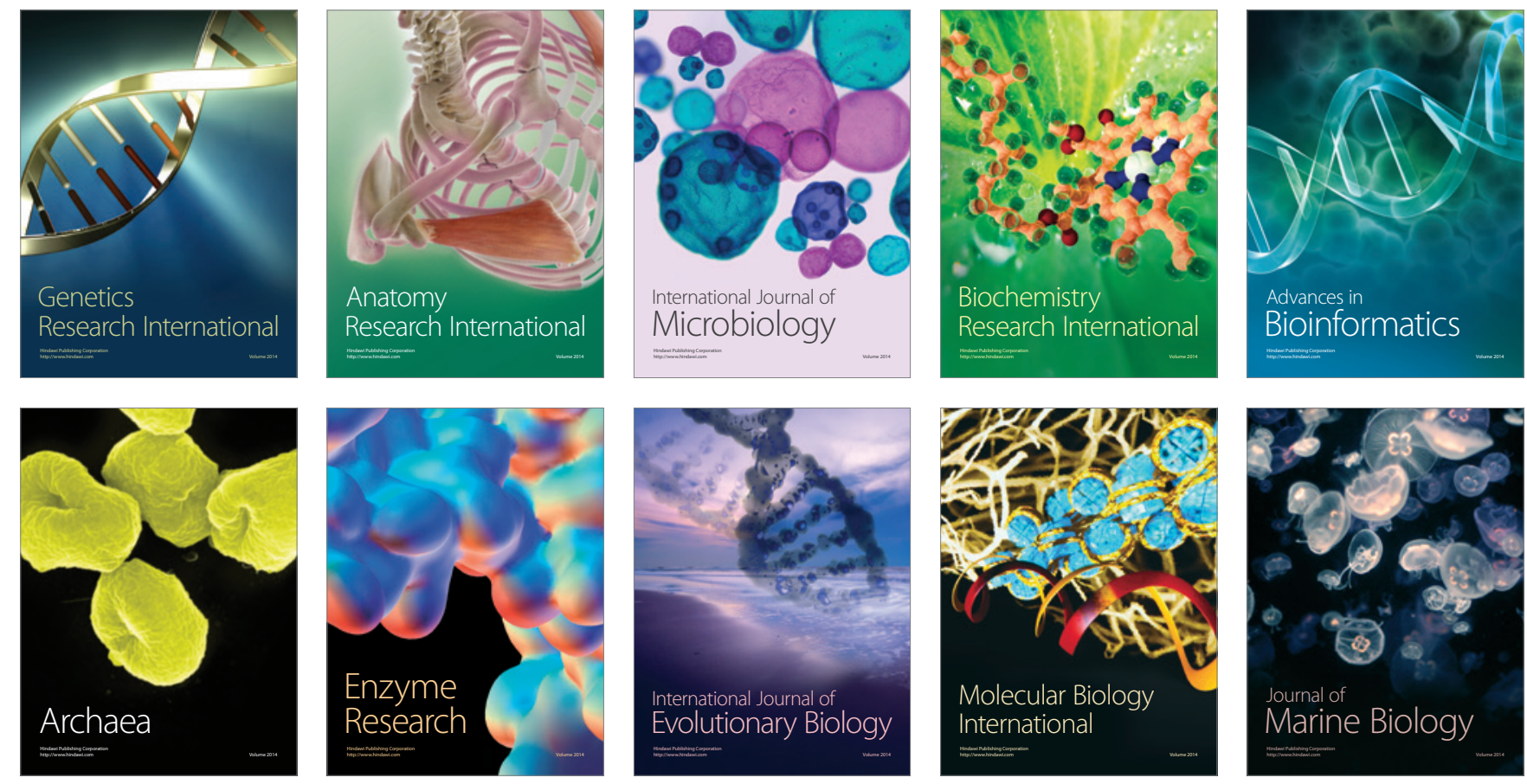